\title{
A mobilidade e a expansão territorial na cidade de São Luís, MA: um novo paradigma social na ocupação do espaço urbano
}

\author{
Mobility and territorial expansion in the city of São Luís: \\ a new social paradigm in the occupation of urban space
}

Marcio Rodrigo da Silva Pereira José O. Alcântara Jr.

\begin{abstract}
Resumo
0 presente trabalho tem como objetivo refletir sobre transformações no campo social e urbano que influenciaram uma mudança de paradigma na ocupação da cidade de São Luís, MA. Relacionam-se fatores históricos ocorridos no espaço urbano com teorias das ciências sociais, considerando que a mobilidade interfere no crescimento da cidade e nas suas relações entre os indivíduos. Procura-se estabelecer um elo entre as infraestruturas viárias urbanas, oriundas de ações do poder público e transformações do comportamento da sociedade contemporânea, considerando a construção social motility, utilizada por Weert, Kauffmann e Kesselring (2008). Por fim, a pesquisa busca contribuir para a compreensão das transformações urbanísticas e sociais, a partir da segunda metade do século XX, na cidade de São Luís.
\end{abstract}

Palavras-chave: mobilidade; expansão; paradigma; social; urbano.

\begin{abstract}
This paper aims to reflect on transformations in the social and urban field that have influenced a change of paradigm in the occupation of the city of São Luís, state of Maranhão. Historic factors that took place in the urban space are related to theories of the social sciences, considering that mobility interferes in the growth of the city and in the relations among individuals. A link is established between urban road infrastructure originating from governmental actions and transformations in the behavior of contemporary society by using motility, the social construction utilized by Weert, Kauffmann and Kesselring (2008). Finally, the study contributes to the understanding of urban and social transformations occurred from the second half of the 20th century onwards, in the city of São Luís.
\end{abstract}

Keywords: mobility; expansion; paradigm; social; urban. 


\section{Introdução}

0 presente trabalho tem por objetivo refletir sobre transformações no campo social e urbano que influenciaram uma mudança de paradigma na ocupação da cidade de São Luís, no Maranhão, durante a década de 1970. Um novo paradigma surge no processo de desenvolvimento urbano naquela época, tendo em vista a ocupação de novos territórios, resultantes de uma série de ações do governo do estado do Maranhão e da prefeitura municipal de São Luís que propiciou a implantação de meios de transportes e infraestruturas viárias, aumentando a escala do deslocamento no tempo e no espaço.

Santos (2013, p. 33) diz que o "forte movimento de urbanização que se verifica a partir do fim da Segunda Guerra Mundial é contemporâneo de um forte crescimento demográfico, resultado de uma natalidade elevada e de uma mortalidade em descenso". Nesse contexto, o processo de industrialização no Brasil tem relação direta com a urbanização e o crescimento populacional nas cidades brasileiras. A grande concentração de indústrias, de forma predominante no eixo centro-sul do País, contribuiu para que a produção do espaço urbano em regiões mais distantes fosse realizada de forma mais lenta.

Com o acelerado processo de urbanização no Brasil, a questão do trânsito e do transporte passou a ter uma nova perspectiva com 0 automobilismo, o que exigiu um posicionamento por parte do Estado, para a criação de políticas urbanas ${ }^{1}$ que permitissem o deslocamento de pessoas e de cargas nas cidades. Mais tarde, toda essa discussão resultaria na construção da
Política Nacional de Mobilidade Urbana, com 0 intuito de contribuir para o acesso universal à cidade (Brasil, 2012).

Souza (2010) infere que, na segunda metade do século XX, a elaboração dos grandes Planos Nacionais de Desenvolvimento proporcionou ações governamentais, com fins políticos e econômicos, destinadas para várias localidades da região nordeste, inclusive para a cidade de São Luís, capital do estado do Maranhão. Essa política desenvolvimentista, proposta pelo Governo Federal, tinha como objetivos realizar a integração do território nacional e criar áreas de dinamização econômica, contribuindo para as transformações urbanísticas e para o aumento populacional em determinadas cidades brasileiras. Desse modo, apresentamos os principais planos urbanos que influenciaram o direcionamento da expansão da cidade de São Luís, tendo em vista a estruturação e a ordenação dos novos usos e ocupação do território.

Procuramos estabelecer uma relação entre o Plano de Expansão Urbana, elaborado pelo Engenheiro Ruy Ribeiro de Mesquita, que foi publicado em 1958, e o Plano Diretor de 1975, ambos determinantes dos objetivos e das diretrizes para o cenário urbano, influenciando as transformações de representações sociais em relação à cidade. Instituir o princípio de refletir sobre essa nova perspectiva nas ciências sociais, enfatizando que a mobilidade urbana passa a ser estudada como um novo paradigma, provocando discussões recentes nas mais variadas áreas das ciências, contribui para a compreensão de um novo padrão de comportamento social, que surgiu ao longo do século passado e cujos resultados são consolidados no meio social urbano do século XXI. 
As formas de estruturas sociais e territoriais apresentam relações que transcendem a estratificação social e o foco espacial. Nesse sentido, a construção social do termo motility (Weert, Kauffmann e Kesselring, 2008) envolve uma análise na relação entre mobilidade espacial e social, descrevendo uma capacidade potencial de coisas e informações, que são capazes de se deslocar no meio social e geográfico. São apontadas três ferramentas relacionadas com aquela categoria: o acesso, a competência e a apropriação, que contribuem para o seu entendimento nas sociedades contemporâneas.

Este artigo empregou esses três aspectos como métodos de análise de transformações do comportamento social, o que permitiu rever questões em debate nas ciências sociais. Motility refere-se às reais condições de acesso social e tecnológico, que as pessoas dispõem para realizar deslocamentos no tempo e no espaço; as competências são habilidades necessárias para aproveitar o acesso; e a apropriação relaciona-se com as ações que o indivíduo faz com o acesso e as competências (ibid.).

Por fim, é de extrema importância entender a análise da mobilidade urbana de uma forma mais ampla, considerando um aporte teórico no campo sociológico e urbanístico, para explicar como um novo padrão de comportamento social surgiu na década de 1970. Essa transformação se reflete até os dias de hoje e tem relação direta com a qualidade de vida da população, alterando de forma significativa a paisagem urbana, considerando que a criação de novos eixos de expansão urbana trouxe resultados significativos na percepção do ambiente construído e nas relações sociais na cidade de São Luís.

\section{A expansão urbana e o sistema de transporte: transformações sociais na cidade de São Luís}

A cidade de São Luís, capital do estado do Maranhão, está situada na Ilha de São Luís, no Golfão Maranhense, entre as baías de São José e de São Marcos, com mais três municípios: Paço do Lumiar, Raposa e São José de Ribamar. Atualmente, a cidade de São Luís possui uma população de 1.014.000 habitantes e uma área de $834,79 \mathrm{~km}^{2}$, resultando numa densidade demográfica de 1.215,69 hab./km² (IBGE, 2016).

Durante a década de 1940, São Luís começou sua expansão para além dos limites do núcleo urbano antigo, que foi proporcionada a partir da implantação dos bondes elétricos até o bairro do Anil, da Ferrovia São Luís - Teresina, e da abertura de novas avenidas, como a Getúlio Vargas e a João Pessoa, facilitando o deslocamento dos indivíduos, por meio de um transporte público, e que organizaram a ocupação de locais mais distantes do Centro, onde estavam situadas chácaras, quintas e sítios (Lopes, 2008).

Miralles-Guasch (2002) diz que a cidade e o transporte, ao longo de sua evolução, se cruzam e se influenciam. Entretanto, geralmente esses estudos se reduzem a uma análise causal, em que um elemento funciona como causa e o outro como consequência. Sabe-se que a análise dessa relação, indiscutível e complexa, passa por uma compreensão profunda das dinâmicas territoriais em que se inserem os meios de transporte.

A mobilidade urbana não pode ser entendida, apenas, com a introdução do transporte 
urbano, como um elemento técnico inserido, de forma mais ou menos coerente, no espaço público da cidade. Ela deve ser vista como uma construção social, na medida em que o aumento da velocidade tem introduzido novos conceitos de espaço e de tempo. Dessa forma, Miralles-Guasch afirma que:

[...] Superar o paradigma da causalidade e introduzir o da dialética implicam conceber que um deles é continuamente produto do outro, e isto significa, como indica Oyón (1999), uma relação recíproca e circular no tempo, em que se destacam as características temporais, espaciais e sociais da relação entre a cidade e os transportes urbanos. Este é um passo importante para entender como e por que os cidadãos se movem sobre um território vital que conhecemos por cidade. (Ibid., p. 11; tradução nossa)

Essa transformação da escala de tempo e espaço nos deslocamentos realizados no meio urbano tem o transporte como elemento estruturador das novas relações a serem desenvolvidas nas cidades. Antes do advento tecnológico, a mobilidade de coisas e pessoas de um local para outro dependia do modo de transporte utilizado e da distância a ser percorrida entre esses lugares. Com o surgimento do veículo motorizado, temos uma grande transformação na escala dessas viagens, que resulta em modificações significativas nas relações sociais, já que se tornou possível percorrer grandes distâncias em menos tempo.

A popularização da produção de automóveis iniciada por Ford, além de ampliar de forma gigantesca o mercado de consumo desses bens e denominar uma nova forma de organização da produção, constituiu-se em uma das revoluções tecnológicas que transformaram não apenas a velocidade, mas também a cultura da mobilidade, fornecendo as bases técnicas e políticas do projeto de cidade. (Rolnik e Klintowitz, 2011, p. 91)

Nobre (2010) analisa a perspectiva do urbanismo, por meio do "rodoviarismo", demonstrando um papel que transcende a forma de organização técnica do território e revela um caráter econômico e político na hegemonia no País. Na primeira metade do século XX, tem-se o "Plano de Prestes Maia" baseado nas vias para o transporte automotivo, o que se tornaria o principal eixo de expansão da cidade de São Paulo. Em 1949, Robert Moses² elaborou o "Plano de Melhoramentos para São Paulo" trazendo:

[...] o modelo da Highway Research Board, o qual pretendia adaptar as cidades para comportar a expansão periférica horizontal em subúrbios residenciais de classe média motorizada. Ao invés de produzir um sistema de autossuficiência, o subúrbio jardim norte-americano acompanhou o desenvolvimento da indústria automobilística, gerando a necessidade de grandes deslocamentos cotidianos para seus habitantes. (Anelli, 2007, p. 4)

Em 1950, o crescimento urbano brasileiro vai ser influenciado por uma série de ações do Governo Federal e Estadual, resultando no aumento das exportações e importações realizadas no estado do Maranhão, principalmente pela implantação de rodovias federais e estaduais, tais como: a BR 010 (conhecida como Belém-Brasília) e a BR 135. Sendo assim, São Luís se tornaria um polo de convergência, canalizando os fluxos migratórios do interior do estado e que continuariam nas décadas seguintes (Ferreira, 2014). 
Miralles-Guasch (2002) comenta que os transportes urbanos surgem paralelamente no início da cidade industrial, quando se constrói um território urbano adequado às próprias condições de produção e de consumo. Essa relação entre estrutura produtiva e estrutura territorial já foi discutida pelos primeiros geógrafos e sociólogos críticos dos anos de 1970, os quais solicitavam condições gerais que permitissem o desenvolvimento de tais estruturas. Nesse sentido, eles argumentam que:

Uma dessas condições é que proporcionam as administrações em forma de políticas públicas, tanto territoriais como setoriais, onde estão incluídas as infraestruturas, uma parte das quais permite e possibilita a mobilidade das pessoas no espaço: os meios de transportes. (Miralles-Guasch, 2002, p. 12; tradução nossa)

A infraestrutura de mobilidade urbana pode ser utilizada para vencer os efeitos da desagregação espacial intrínseca na evolução da cidade. Desse modo, o uso necessário dos meios de transportes confere a criação de uma estrutura social, vinculada a um sistema econômico. De acordo com Miralles-Guasch (ibid.), isso se converte num elemento integrado no conjunto de infraestruturas públicas necessárias, mas não é suficiente para o desenvolvimento da cidade moderna, pois os meios de transportes são uma parte da envoltura socioeconômica que os utiliza em face de suas próprias necessidades e conflitos.

Desde o século XIX, o paradigma da causalidade tem acompanhado todas as análises que pretendiam estudar as infraestruturas de transportes como um elemento inserido no território concreto. Esse enfoque foi reforçado a partir da década de 1950, quando as ciências sociais, tanto no plano teórico quanto conceitual, adotaram a filosofia e a lógica neopositivista, caracterizadas pela vontade de formular leis gerais, empiricamente gerais por meios de modelos matemáticos explicativos e do uso exclusivo daqueles elementos que assegurassem um conhecimento objetivo das ciências sociais (ibid.).

0 engenheiro Ruy Ribeiro de Mesquita elaborou o plano de expansão da cidade de São Luís, que foi publicado em 1958. Naquela época, ele afirmava que a implantação da cidade entre dois grandes rios, Anil e Bacanga, e a grande quantidade de igarapés facilitavam a pequena navegação como um dos meios de transportes mais favoráveis. Entretanto, o mar bravo era um inconveniente para a chegada das navegações no porto na área central da cidade. Sendo assim, ele comenta que:

[...] É fácil concluir que boas estradas de rodagem, ligando as zonas rurais com a cidade e em articulação com os demais sistemas de viação (férrea, fluvial e marítima), constituirão um sistema básico para o desenvolvimento e o progresso da ilha de São Luís. (Mesquita, 1958, p. 1)

No plano de expansão de São Luís de 1958, Mesquita comenta sobre a obra de Roberto Galvão, que foi intitulada de "Introdução ao conhecimento da área maranhense abrangida pelo Plano de Valorização Econômica da Amazônia", demonstrando que a expansão da cidade ocorreu pela parte mais alta do relevo, e, após a formação dos bairros de Remédios e São Pantaleão, o crescimento urbano ocorreu em direção da estrada, que, no período, era a única saída para o continente e para o interior da ilha, denominada "Caminho Grande". 
Assim, de acordo com Mesquita (1958, p. 1) são definidas três fases de ocupação na cidade, que foram sistematizadas da seguinte maneira: no século XVII, houve a formação do núcleo urbano; no século XVIII e início do século XIX, a constituição do bairro central (atual centro histórico); e, por fim, no século XIX, a formação dos bairros excêntricos.

Para Miralles-Guasch (2002), o determinismo tecnológico, como explicação da estrutura espacial urbana, aparece de forma recente nos trabalhos que analisam a cidade e, sobretudo, naqueles que fazem referência aos transportes urbanos. Segundo essa teoria, a evolução e a mudança originadas nas estruturas urbanas, tanto do ponto de vista formal quanto funcional, dependeriam do avanço tecnológico, os quais seriam responsáveis pela organização das atividades humanas e por estruturar as relações sociais.

Atualmente, alguns autores como Canzler, Kauffmann e Kesselring (2008) colocam em discussão alguns aspectos sobre os deslocamentos dos indivíduos no espaço urbano, realizando críticas sobre os objetivos de os movimentos serem reduzidos a um só: 0 trabalho. Sendo assim, é necessário superar a rigidez desse argumento, explicando o desenvolvimento da relação entre o território urbano e os meios de transportes, através dos paradigmas estruturantes dessa relação tão complexa. A dimensão espacial abrange o campo urbano e morfológico, considerando diferentes dimensões, o que leva à definição do termo motility como:

[...] a capacidade de uma pessoa se mover socialmente e espacialmente. Isto é, portanto, reforçado por conexões que podem ser definidas como todas as formas de acesso obtidas (tecnologicamente e socialmente), as habilidades adquiridas para conseguir vantagens desse acesso, e sua apropriação (o que a pessoa faz com esse acesso e essas habilidades). Consequentemente, motility é como um indivíduo ou grupo subscreve o campo de possibilidades e seus usos, também se referindo intencionalmente. (Canzler, Kauffmann, Kesselring, 2008, p. 3; tradução nossa, grifo nosso)

A organização do espaço urbano envolve atividades cotidianas e pontuais, fazendo com que as políticas de transporte e a disposição do território urbano possam funcionar como instrumentos de inserção ou de exclusão. As configurações desse espaço, considerando a mobilidade urbana, levam-nos ao homem moderno com atitudes que seguem um novo padrão de comportamento na sociedade. Sendo assim, a mobilidade é uma soma de deslocamentos realizados pelos indivíduos, razão pela qual a sua análise não pode ser apenas voltada ao transporte, mas também devem ser incluídas as pessoas como integrantes dessas principais ações.

Como em qualquer ação individual ou coletiva, o desenho de políticas de transporte urbano e a construção de infraestruturas são sempre elementos contextuais, ou seja, não são conjuntos aleatórios de acontecimentos, sendo expoentes de diferentes agentes ou atores ligados ao espaço e ao tempo e que atuam numa conjuntura social específica. De acordo com Miralles-Guasch, essa contextualização é integrada por três esferas diferentes: a econômica, a política e a social, mas são complementares entre si.

A econômica, caracterizada pelo industrialismo, em cada uma de suas fases, é organizada segundo os princípios gerais 
da produção capitalista. A política, dominada pelo Estado, que se utiliza de um complexo de mecanismos institucionais, democráticos ou não, para exercer o controle social e político, superar as crises e assegurar a continuidade da produção econômica. A social, o marco da sociedade civil, que integra o conjunto de atuações, relações sociais e culturais e as instituições políticas. (Miralles, 2002, p. 25; tradução nossa)

A mobilidade como instrumento de política por parte do poder público é de extrema importância para o novo cenário urbano imposto pelo processo de Revolução Industrial que trouxe avanço no desenvolvimento de tecnologias. A percepção social dos seres humanos sofreu impacto significativo, pelo fato de ultrapassar as barreiras físicas e territoriais, por meio de inovações tecnológicas oriundas do processo de industrialização, que abrangem princípios gerais do sistema capitalista, refletidos na face econômica, política e social de nossa sociedade.

Urry (2007, p. 3) diz que "o mundo inteiro está em movimento, com inúmeros meios de transporte e comunicação, como: mensagens, textos, websites, ônibus, carros, trens", entre outros. Considera que a escala dessas viagens é imensa e que existem múltiplos aspectos de mobilidade envolvidos na sociedade contemporânea. Como atores desses deslocamentos, destaca, por exemplo: os aposentados, os executivos, os estudantes internacionais, os membros de diáspora, os turistas, as celebridades do esporte, os terroristas, os escravos.

0 termo mobilidade pode ter diferentes significados: primeiro, o uso de móvel significa que alguma coisa que se move ou que é capaz de movimento, ou seja, é uma propriedade de coisas e de pessoas; segundo pode representar uma multidão indisciplinada, e desordenada, e que precisa ser monitorada e regulada socialmente; o terceiro pode ter um sentido de senso voltado à mobilidade social, representando uma estrutura verticalizada. Por fim, a mobilidade pode estar relacionada ao senso de migração ou a outros tipos de movimentos geográficos semipermanentes (ibid.).

Analisando os vários sentidos de mobilidade, devemos examinar as mais variadas consequências para diferentes pessoas e lugares que podem interferir de formas variadas na vida social. As novas tecnologias de transporte e de comunicação caracterizam as sociedades modernas; no entanto uma consequência dessa situação é que o movimento físico pode, em certas ocasiões, ser menos necessário. Nesse sentido, Urry aponta que:

[...] 0 sistema de automóvel é mais do que um modo de vida, de organização econômica, de vida social e cultural, que somente em parte envolve o movimento de pessoas de um lugar para outro. Nós o vemos como um sistema autopoiético, extraordinariamente adaptativo, expandido e capaz de dominar outro sistema, transformando continuamente 0 ambiente que os outros operam. (Ibid., p. 110; tradução nossa)

Conforme Urry (2008), a mobilidade adquire uma característica importante de experiência cotidiana, e os deslocamentos virtuais e/ou geográficos resultam em transformações radicais nos modos de vida, abrangendo esferas políticas, econômicas, sociais e culturais. $A$ mobilidade é vista como um novo paradigma nas ciências sociais, o qual examina os sistemas lógicos da circulação de pessoas e de 
mercadorias, considerando as relações sociais na sociedade contemporânea, que podem ser analisadas a partir da mobilidade individual. Nesse contexto, Urry realiza uma análise sobre o primeiro elemento do paradigma que

considera toda a relação social como diversas "conexões" necessárias, considerando mais ou menos "à distância", mais ou menos a rapidez, mais ou menos a intensidade e mais ou menos a circulação física envolvida. As relações sociais nunca estiveram somente fixadas ou localizadas no lugar, mas estão em muitos diferentes níveis, constituídos por diferentes entidades que criam uma relação dentro e entre as sociedades em múltiplas e variadas distâncias. (Ibid., p. 13; tradução nossa)

As motivações de aquisição e de consumo são alteradas, pois sofrem interferência dos fluxos de mobilidade e de suas consequências nas dinâmicas culturais, econômicas e políticas da sociedade contemporânea. Atualmente, a vida social globalizada envolve deslocamentos físicos e virtuais que criam novos tipos de relações presenciais ou não presenciais, mediados por bens e serviços que organizam a circulação de pessoas, além de objetos e informação, em variados alcances espaciais e com velocidades distintas (ibid.).

Na cidade de São Luís, a ocupação urbana ficou restrita basicamente ao núcleo fundacional de 1612 até 1950; assim a cidade cresceu numa pequena área geográfica, entre os rios Anil e Bacanga. As propostas contidas no Plano de Expansão da Cidade de São Luís, de 1958, tinham muito do que foi proposto no Plano Rodoviário da Ilha de São Luís, elaborado oito anos antes pelo engenheiro Ruy de Mesquita. Entre essas proposições estava a indicação da construção de uma ponte sobre o rio Anil, ligando o Centro Histórico ao que seria 0 atual bairro do São Francisco.

A Figura 1 mostra o mapa elaborado por Mesquita, com as vias de deslocamento no meio urbano. Ele apresentou elementos viários, tais como: estradas de rodagem e de ferro, existentes e a serem projetadas; além dos acessos para municípios da Raposa e de São José de Ribamar. Um aspecto interessante identificado no mapa é a proposta de uma via na orla marítima situada entre a região do Calhau e do Olho d'Água, onde atualmente existe a avenida Litorânea. Muitas das proposições do plano não foram executadas logo de imediato, algumas só seriam realizadas pelos governos posteriores.

Houve a indicação de construções das pontes sobre osrios Anil e Bacanga. Ultrapassar a barreira do rio Anil significava permitir o deslocamento das pessoas, por meio de veículos automotivos, do centro (núcleo fundacional) para a parte norte da ilha, ocupando as áreas situadas entre a orla marítima e o rio Anil. Para isso, foi proposto um traçado ortogonal de vias entre as localidades da Ponta d'Areia, São Marcos e Vinhais, resultando numa nova configuração de divisão territorial e definindo uma nova morfologia urbana, para uma área que não tinha sido ocupada de forma efetiva.

A ponte e a barragem sobre o rio Bacanga buscavam ligar a parte central com a parte sul e sudoeste da Ilha, onde mais tarde seriam implantados o porto do Itaqui e um distrito industrial. Entretanto, foram realizados um aterro e a construção de uma barragem, sendo esta a única infraestrutura rodoviária que permite o deslocamento mais rápido do Centro Histórico para essas áreas, até os dias de hoje. Dessa 
forma, o núcleo fundacional torna-se um eixo de conexão intermediária entre os deslocamentos de pessoas que ocupam a porção norte da
Ilha, situada na região da orla marítima, e a parte oeste-sul que engloba a região do Distrito Industrial e do Maracanã.

Figura 1 - Plano de expansão da cidade de São Luís

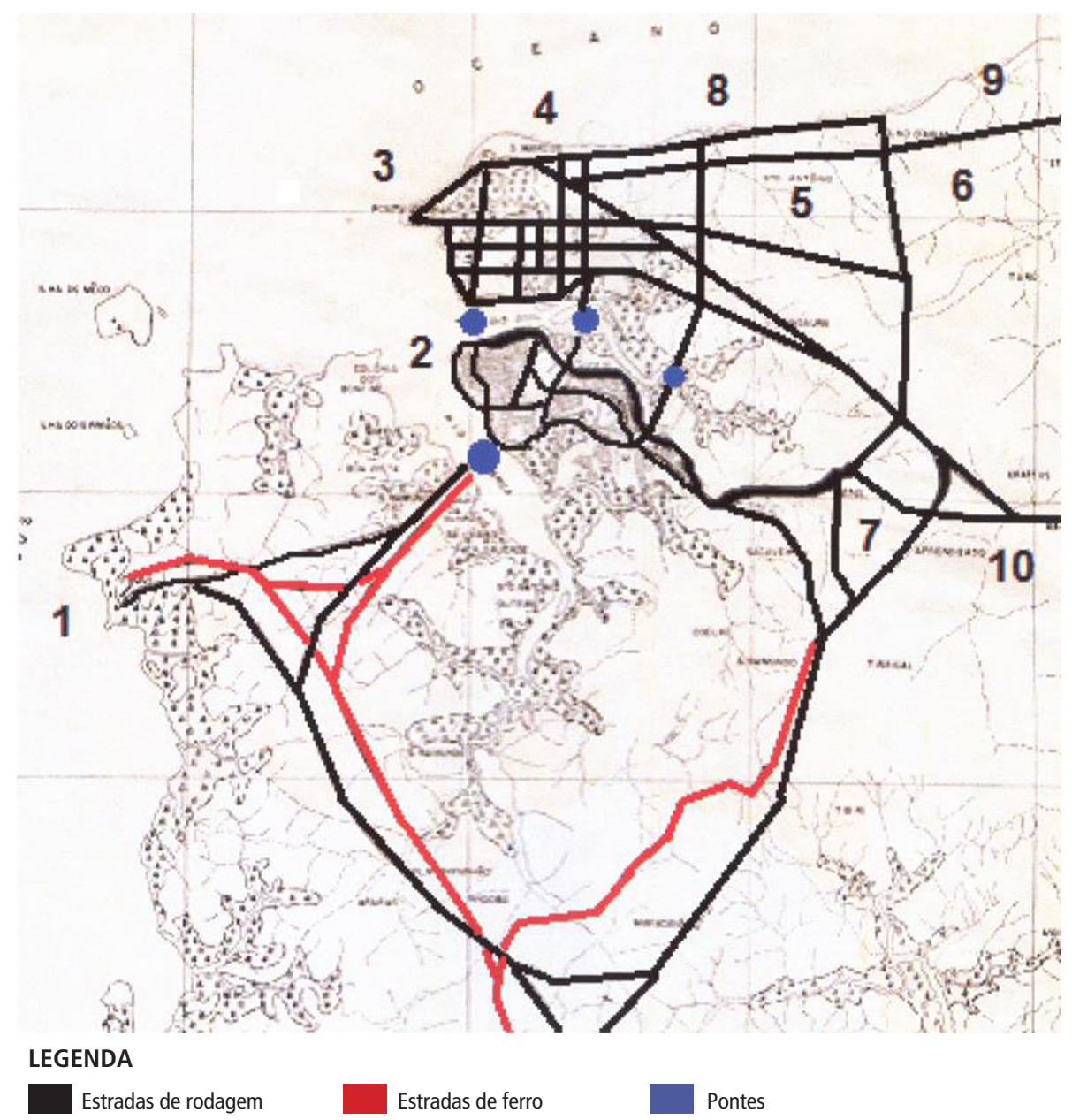

(1) Porto do Itaqui; (2) Centro Histórico; (3) Ponta d'Areia; (4) São Marcos; (5) Calhau; (6) Olho d'Água; (7) Anil; (8) Avenida Litorânea; (9) Acesso ao município da Raposa; (10) Acesso ao município de São José de Ribamar.

Fonte: Mesquita (1958); adaptado pelos autores. 
Figura 2 - Ponte sobre o rio Anil, ligando o Centro Histórico ao futuro bairro do São Francisco

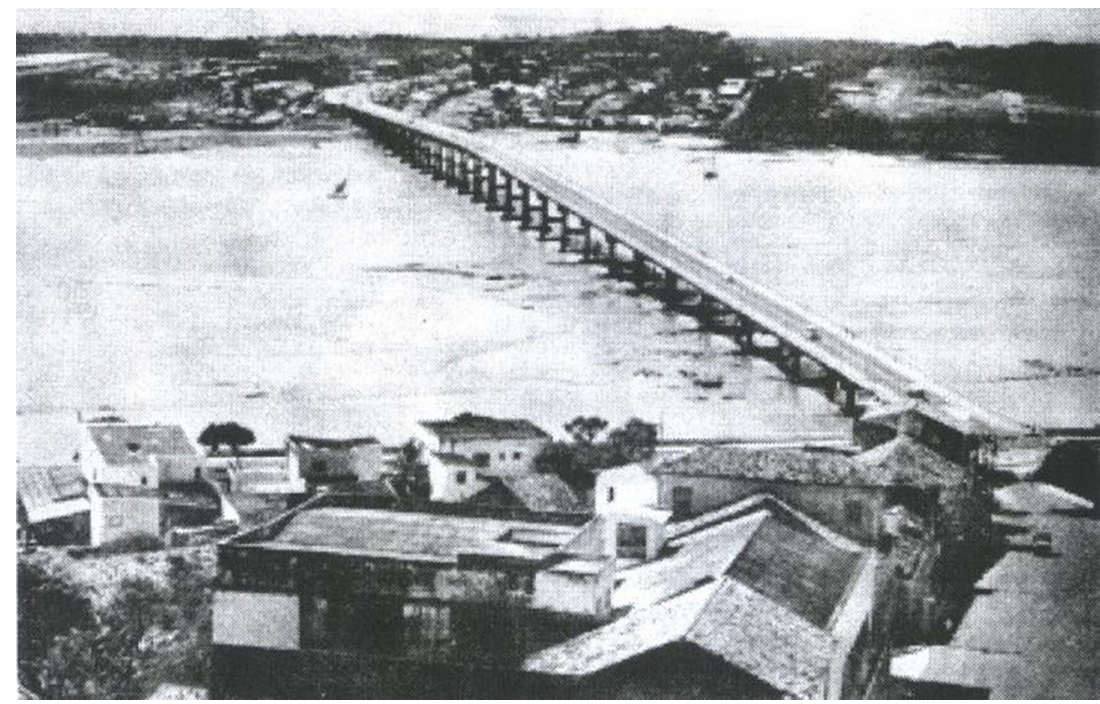

Fonte: Maranhão (1977).

Figura 3 - Ligação de parte do futuro anel viário com a barragem do Bacanga

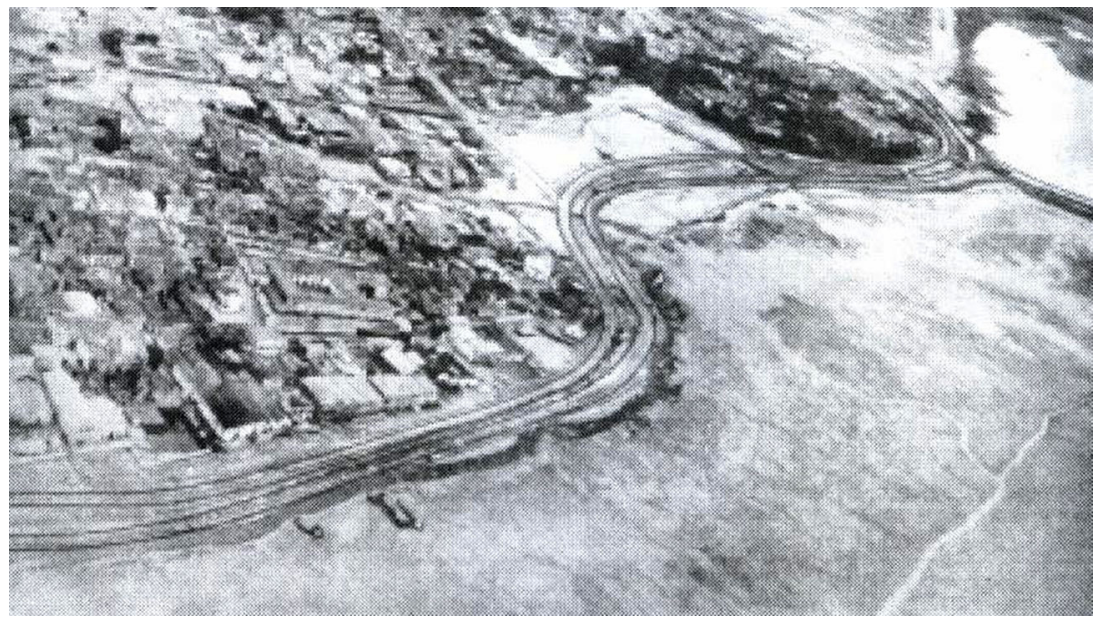

Fonte: Maranhão (1977). 
Mesquita (1958, p. 2) apontava aspectos positivos na ligação da cidade com a área do Itaqui e Maracanã, pois ela contribuiria para a conservação do acervo edificado de arquitetura colonial portuguesa e facilitaria o fluxo de veículos fora da área do núcleo fundacional da cidade. Esse pensamento demonstrava possíveis preocupações com as transformações modernistas ocorridas no centro da cidade, tais como: a abertura da avenida Magalhães de Almeida e a construção do edifício do Banco do Estado do Maranhão (BEM), que possuía 10 pavimentos. Cafeteira (1994) na sua obra Reviver reforça a ideia de que a construção de pontes sobre o rio Anil e a barragem do Bacanga, no rio de mesmo nome, seria fator de extrema importância para conservação do acervo arquitetônico do Centro Histórico, que posteriormente seria tombado pela Unesco. ${ }^{3}$

Burnett (2008) analisa a nova proposta urbanística de Mesquita, por meio do caráter dos eixos rodoviários apresentados no plano rodoviário de 1958, que tinha como proposição a separação nas funções da cidade e direcionava o crescimento urbano para novos territórios, seguindo um padrão funcionalista do urbanismo moderno, e que seriam incluídos nos estudos do plano diretor de 1975. Nesse contexto, Burnett (2008) conclui que:

[...] Ao encarar o problema do crescimento da cidade e sua relação com o Centro Histórico, Ruy Mesquita (1958) apresenta pela primeira vez para São Luís as propostas de planejamento de larga escala e parte, decididamente, em busca da conquista territorial. (p. 125)

O II Plano Nacional de Desenvolvimento, instituído no governo de Ernesto Geisel, já apresentava intenções de políticas voltadas para a preservação de centros históricos das cidades brasileiras, para isso foi proposta "a ordenação da ocupação da orla marítima, preservando-se o patrimônio histórico e valorizando-se a beleza paisagística, com vistas ao desenvolvimento do turismo interno e internacional" (Brasil, 1974, p. 70). Esse plano procurava alcançar o desenvolvimento acelerado das cidades da região nordeste, bem como estabelecer o controle e a organização do processo de expansão metropolitano. 0 crescimento das atividades produtivas e a melhoria da infraestrutura urbana faziam parte do processo de dinamização dos núcleos urbanos regionais. Assim o plano tinha como uma das estratégias:

[...] A implantação de programas de planejamento integrado, de reforço da infraestrutura econômica e dos equipamentos sociais da cidade que recebem grandes projetos industriais, destacando-se, na Região Metropolitana de Salvador, o polo petroquímico de Camaçari, no estado do Maranhão, a cidade e a ilha de São Luís e o Porto do Itaqui, e ao sul da cidade do Recife, o Porto do Suape. (Ibid.)

0 plano de expansão para o desenvolvimento de São Luís de 1958 criou um desenho urbano na área compreendida entre o rio Anil e o mar, definindo cinco zonas que eram destinadas aos usos social, administrativo, comercial e residencial. Esse zoneamento proposto para ocupação do novo território já determinava a divisão em setores de acordo com a renda do indivíduo, pois criou zonas residenciais com as seguintes designações: "de luxo" e de "primeira classe", que seriam destinadas àquelas camadas sociais com um alto poder aquisitivo. Essas zonas nobres ocupavam parte do território com vista para a orla marítima, onde 
atualmente se encontram os bairros da Ponta D'Areia e de São Marcos, enquanto as zonas residenciais de "segunda e terceira classes" ocupariam a parte mais central da área, que hoje é ocupada pelos bairros Renascença I e II (Mesquita, 1958).

Algumas áreas foram destinadas para a implantação de edificações voltadas ao lazer e à cultura, como teatros, hotéis e cinemas, onde atualmente se encontram localizados 0 bairro do São Francisco e da Ponta D'Areia. Definiram-se espaços públicos como praças, jardins, mercados e praça da administração (dos três poderes), com edifícios de até 10 pavimentos para o executivo, legislativo, judiciário, secretarias e repartições do Estado. 0 plano destacava as edificações institucionais, pois apresentava uma nova configuração espacial e o aumento do gabarito para esses respectivos usos.

Figura 4 - Plano para o desenvolvimento de São Luís

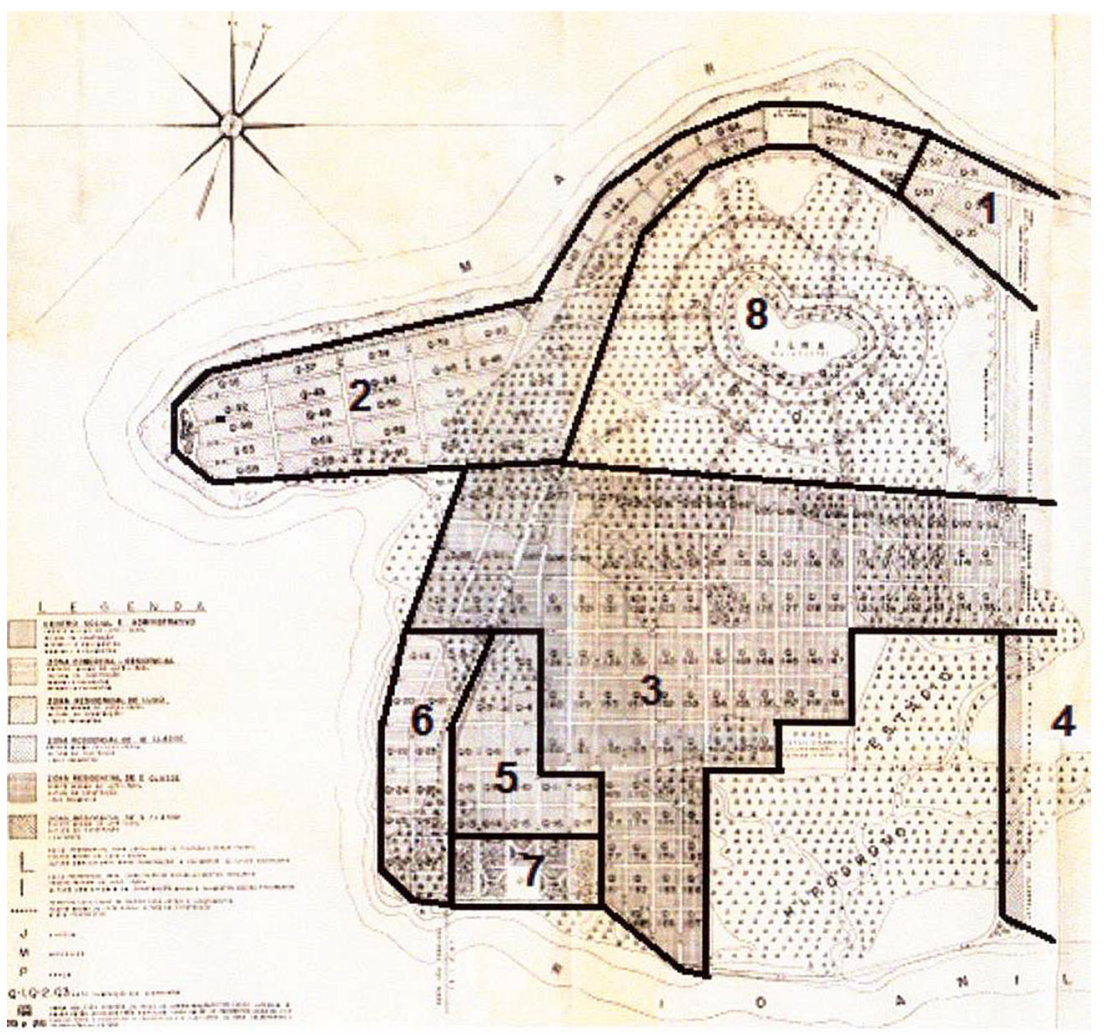

Fonte: Mesquita (1958), adaptado pelos autores.

Legenda:

(1) ZR* de luxo; (2) ZR de $1^{\text {a }}$ classe; (3) ZR de $2^{\text {a }}$ classe; (4) ZR de $3^{a}$ classe; (5) Centro social e administrativo; (6) Zona Comercial e Residencial; (7) Jardim - Praças; (8) Lagoa da Jansen.

* Zona Residencial (ZR). 
0 zoneamento proposto para a ocupação desse novo território, apesar de não ter sido o seu objetivo principal, apresentou alguns aspectos que podem ter contribuído para um processo de segregação socioespacial, já iniciado naquela época e que hoje é facilmente percebido na cidade de São Luís. A partir do momento que são delimitadas áreas exclusivas consideradas de luxo e de primeira classe, e que ocupam a orla marítima com vista privilegiada do mar, proporciona-se ao mercado imobiliário oferecer uma nova mercadoria no setor habitacional, com características peculiares das cidades litorâneas.

Outro aspecto a ser considerado é que esse instrumento urbanístico contribuiu para um novo padrão comportamental na sociedade de São Luís, em que a classe com mais alto poder aquisitivo buscou ocupar áreas que possuíam características exclusivas locacionais e até mesmo de paisagens naturais, como a praia e a vista para o mar. Isso permitiu que ocorresse a valorização do solo urbano de determinados setores em relação aos outros, iniciando o processo de especulação imobiliária.

Segundo Villaça (2001) as cidades brasileiras litorâneas têm, em grande parte, suas orlas marítimas ocupadas pelas camadas de mais alta renda. Esse processo de ocupação não ocorreu de modo simultâneo, surgindo primeiro nas cidades do Rio de Janeiro e de Santos. No final do século XIX, a elite urbana carioca morava fora da cidade, num estilo de casa chamada de chácara, comum nas antigas capitais brasileiras. A mobilidade territorial urbana proporcionou a:

[...] localização fora da cidade de parte da população de alta renda do Rio de Janeiro na primeira metade do séc. XIX. Importa saber até que ponto as chácaras eram domicílios permanentes - ou quase - de moradores urbanos - embora localizados além dos tentáculos suburbanos -, isto é, ocupados por famílias cujos membros, especialmente o chefe, exerciam profissão urbana, tinham estilo urbano de vida e/ou usavam e frequentavam a cidade e, por isso, para ela se deslocaram com muita constância, talvez quase diariamente. A distinção não é simples, pois entre estabelecimentos claramente rurais e claramente urbanos há uma penumbra de gradações. (p. 161)

A cidade do Rio de Janeiro apresentou uma etapa em que a organização social (inclusive com escravidão) e os meios de transporte eram tais que faziam com que significativas parcelas das elites urbanas morassem fora da cidade. Na passagem do século XIX para 0 $X X$, começou a se desenvolver no Rio um hábito já difundido na Europa: o banho de mar. Com as praias saneadas, essa transformação cultural se difundiu e começou a ser valorizado um atributo do sítio natural até então desprezado: a proximidade da praia e a vista para 0 mar. Villaça (ibid.) analisa que:

[...] Antes, a orla oceânica fora atraente apenas aos ingleses, não tanto pelo banho de mar; mais por seu clima e beleza que eles não cansavam de admirar. Agora, não. 0 novo hábito se instala e se difunde. Na Europa que se modernizava, as estradas de ferro tiveram um enorme impacto sobre o desenvolvimento dos balneários do Mediterrâneo e sobre a difusão do hábito do banho de mar; para eles e seus luxuosos hotéis, deslocava-se não só a aristocracia francesa, mas principalmente a austríaca, alemã e a inglesa (donde o nome "Promenade dês Anglais", à beira-mar de Cannes). (p. 177) 
A partir do século $X X$, os bairros situados na orla marítima do Rio de Janeiro reuniram um excepcional conjunto de vantagens locacionais e naturais, passando a ser uma área de disputa das elites. Desde que completou sua primeira etapa de ocupação, por volta da década de 1920, a orla marítima carioca sofreria profundas e rápidas transformações no ambiente construído, no uso do solo e nas classes sociais que se sucederiam na ocupação desses territórios (ibid.).

A ocupação da orla marítima pelas elites foi uma tendência que se dissipou do Rio de Janeiro para todas as outras cidades brasileiras litorâneas. Seguindo essas disposições, o Departamento de Estradas e Rodagens (DER-MA) iniciou a elaboração de planos de expansão urbana na cidade de São Luís, com o intuito de implantar a infraestrutura rodoviária, que permitiria o deslocamento da população das áreas centrais para aquelas próximas ao mar. Portanto, parte da população teria acesso àquelas regiões mais distantes do Centro Histórico, já que não se trataria de um simples deslocamento espacial, considerando que as competências econômicas dos indivíduos seriam fundamentais para conseguir vantagens sociais e espaciais nos novos eixos de expansão urbana.

As diretrizes do Plano de Expansão de Ruy de Mesquita de 1958 indicavam uma nova forma de ocupação do território, tendo em vista expandir em direção à orla marítima, seguindo os princípios urbanísticos de outras cidades litorâneas brasileiras. A criação de um novo padrão comportamental fez com que a classe com alto poder aquisitivo ocupasse áreas que possuíam características exclusivas locacionais e até mesmo de paisagens naturais, como a orla marítima com vista para o mar, a margem do rio Anil e a Laguna que seria criada, hoje conhecida como Lagoa da Jansen. Isso resultou na valorização do solo urbano de determinados setores em relação a outros, fomentando o processo de diferenciação do valor do solo urbano.

As motivações de aquisição e de consumo foram alteradas, pois sofreram interferência dos fluxos de mobilidade e de suas consequências nas dinâmicas culturais, econômicas e políticas da sociedade contemporânea. Atualmente, a vida social globalizada envolve deslocamentos físicos e virtuais, cria novos tipos de relações presenciais ou não presenciais, sendo mediada por bens e serviços que organizam a circulação de pessoas, além de objetos e informação, em variados alcances espaciais e com velocidades distintas (Urry, 2008).

0 zoneamento é um instrumento destinado a organização e definição de funções específicas no território, com a finalidade de organizar usos e ocupação do solo urbano. Entretanto, se não utilizado de maneira adequada, pode causar a valorização da terra e definir zonas de segregação socioespacial na cidade. Nesse sentido, um novo padrão cultural se incorpora na vida urbana de São Luís, definindo características de exclusividades de uso do mercado imobiliário e incentivando a verticalização nesses novos territórios, determinados pelo Plano de Expansão de 1958. Rolnik (1977) afirma que:

[...] a verticalização tem sido uma estratégia para atualizar áreas altamente valorizadas da cidade e a expressão (juntamente com os loteamentos exclusivos) de um dos extremos de um mercado dual. 0 outro extremo, às vezes mais lucrativo que os próprios empreendimentos ricos, era a expansão não regulada na zona rural. (p. 129) 
0 plano de expansão da cidade de São Luís do ano de 1958 forneceu subsídios para o Plano Rodoviário da Ilha de São Luís, que foi instituído pela lei n. 1332, de 27 de dezembro de 1962, e o Plano Diretor de 1975. Essa perspectiva de ocupação advinda da década de 1950 influenciou a elaboração de novas políticas e legislações urbanas, instituindo uma nova convivência comportamental no meio urbano, induzida pela novidade da paisagem urbana construída.

Se até os anos de 1970 a cidade cresceu seguindo o Caminho Grande até o Anil, ocupando a porção central do território, em um processo cumulativo de agregação ao tecido urbano tradicional; com a construção da ponte e da barragem seriam ocupados novos territórios. A barragem do Bacanga permitiu a ocupação do bairro Anjo da Guarda, que foi loteamento implantado para abrigar a população de palafitas situadas numa área conhecida como Goiabal e que tinha sido desabrigada na época por ocasião de um incêndio (Lopes, 2008).

Esse novo padrão de ocupação, já proposto por Mesquita, começou a ser possível pela execução de infraestruturas viárias por parte do Estado e pela implantação de uma nova política de transporte que foi responsável pelo deslocamento das pessoas por esses equipamentos urbanos. Para Lopes (2008), outro vetor de crescimento foi determinado:

[...] pela implementação do sistema viário urbano em fins da década de 1960, especificamente no período de 1967 a 1970, possibilitando 0 crescimento ao sudoeste e ao norte, com a construção respectivamente da barragem do Bacanga (1970), fazendo a ligação entre a área central de São Luís e o Porto do Itaqui, e construção da segunda ponte sobre o Anil, Ponte Governador José Sarney (1971). (pp. 35-36)

Por um lado, percebe-se como a infraestrutura viária determinou o fluxo de pessoas no território, definindo a ocupação da orla marítima por uma classe de poder aquisitivo mais elevada; por outro, verifica-se que a barragem do Bacanga, apesar de ter como objetivo a ligação do centro com o porto do Itaqui, permitiu que parte da população sem acesso às áreas da orla marítima ocupasse as proximidades do porto do Itaqui e do distrito industrial.

Considerando a área nobre da cidade, tendo em vista os novos padrões de moradia e planejamento que adotava, 0 bairro do São Francisco apresenta o traçado urbano ortogonal estruturado por grandes avenidas, típico do urbanismo modernista, onde se implantaram quadras maiores e edificações soltas nos lotes. Para 0 sul, próximo à área industrial, a barragem do Bacanga propiciou a transferência da população de baixa renda que ocupava assentamentos espontâneos e palafitas na área central. (Ibid., p. 292)

A orla marítima passa a ser ocupada por uma classe com poder econômico mais elevado, enquanto as partes sul e sudoeste se configuram por assentamentos de origem informal, iniciados por trabalhadores com baixo poder aquisitivo e que não possuem acesso a uma moradia de qualidade, e que também não é ofertada pelo Estado. Surgem os conjuntos habitacionais, como uma política de habitação ao trabalhador, implantados em locais muito distantes do centro da cidade, representando um tempo muito maior de deslocamento do que aquelas ocupações próximas ao centro. 
No início da década de 1970 é destinada, à Surcap, ${ }^{4}$ uma área de 3.690 ha., denominada Gleba Rio Anil, da Ponta d'Areia e São Francisco até a Avenida São Luís Rei de França, no Turu. Nessa área foram construídos os conjuntos Cohafuma, Cohama, Ipase, Ipem e outros. (Ibid. p. 292)

Assim, nos anos 1970, a capital maranhense vive uma nova expansão urbana, agora em direção ao norte da ilha. Com a construção da ponte do São Francisco, o centro liga-se à orla marítima. Essa intervenção foi complementada pela construção da avenida Maestro João Nunes, ${ }^{5}$ que ligou os bairros do São Francisco e Ponta d'Areia, criando uma laguna, com um espelho d'água de $3,5 \mathrm{~km}^{2}$, resultado do represamento das águas da maré pelo aterro sobre o Igarapé da Jansen. Lopes comenta que:

[...] Este vetor de expansão proporcionou um novo processo de abandono do centro. Além disso, a construção da barragem do Bacanga e a construção do Porto do Itaqui contribuíram para retirar da Praia Grande todo o trabalho de estiva, ficando somente o movimento ribeirinho com as embarcações que fazem o trajeto interiorano. (Ibid., p. 36)

0 objetivo do Plano Diretor de São Luís de 1975 constituía-se no esforço de fornecer, à cidade e à sua área, os elementos básicos para um processo de planejamento coerente, tendo como objetivos: proporcionar a São Luís condições para receber o impacto dos grandes investimentos programados; estabelecer uma política adequada de uso da terra; definir as condições de equilíbrio entre a ocupação e o meio ambiente; indicar hipóteses de desenvolvimento urbano, de modo a obter uma utilização racional das diferentes áreas, mesmo fora dos limites municipais; promover a adequação dos mecanismos da administração municipal ao sistema de planejamento proposto; e estimular a coordenação intergovernamental para o desenvolvimento das funções urbanas e regionais de São Luís (Maranhão, 1977).

Entre os objetivos específicos do plano diretor da época, podemos citar: o fornecimento das diretrizes para o uso da terra e o zoneamento; a definição dos parâmetros de proteção do meio ambiente, em seus aspectos ecológicos e estéticos; o estabelecimento das bases de um plano de transportes; e a valorização do patrimônio histórico. Além disso, o zoneamento proposto tinha uma:

(...) estratégia de desenvolvimento urbano compatível com as tendências de crescimento demográfico e urbano em geral, e que permita orientar a organização espacial de maneira a obter a meIhoria da qualidade de vida e o aumento da eficiência na provisão de serviços urbanos. 0 conceito de qualidade de vida engloba aspectos como melhoria dos padrões de ocupação residencial, aumento de quantidade e qualidade do equipamento, infraestrutura da cidade e aquisição da casa ou lote próprios, enquanto o conceito de eficiência econômica se relaciona com minimização de custos, aumento de produtividade e economias de escala. (Ibid., p. 7)

Foram previstas algumas medidas econômicas na escala da provisão de infraestrutura urbana no território, como o aumento do número de consumidores por área geográfica, ou seja, através do adensamento dos agrupamentos residenciais. Dessa forma, podia-se minimizar as distâncias de viagem de trabalho e 
os custos de transporte, já que a população se concentraria nos bairros próximos aos centros de emprego.

0 objetivo de estimular a aquisição de propriedades requeria a identificação de padrões de ocupação compatíveis com os níveis de renda existentes, levando em conta a área de construção residencial por habitante e a área do lote. No caso de São Luís, isto implicava fomentar parcelamentos de lotes pequenos $\mathrm{e}$, consequentemente, num maior adensamento de certas áreas (ibid.).

A oferta de terra para futura expansão não constitui problema nessas zonas, em virtude da existência de diversas áreas vazias, principalmente nas proximidades do bairro do Anil, cuja ocupação não apresenta problemas. Além disso, as áreas periodicamente inundáveis na margem direita do Bacanga tornaram-se passíveis de urbanização com a construção da barragem nesse rio.

A presença de grandes áreas urbanizáveis e de densidade bastante baixas assim como a grande acessibilidade (fácil acesso à siderúrgica, à zona industrial e ao centro) indicam a conveniência de canalizar a maior parte do crescimento habitacional para a zona residencial ZR-5. (Ibid., p. 15)

Em relação aos transportes, no plano diretor de 1975 constava que os "modelos de transportes", desenvolvidos nos Estados Unidos e na Europa, durante a década de 1960, apesar de disporem de uma metodologia muito avançada, não poderiam ser aplicados em São Luís em face das grandes mudanças físico-econômicas pelas quais a cidade passou naquele período. Os estudos realizados para o plano informavam existir 8.965 veículos licenciados no município de São Luís em 1973, sendo 1.566 de aluguel, 6.540 particulares e 858 de placa oficial. Sendo assim, o aumento do número de automóveis particulares teria maior influência no crescimento da frota, produzindo forte impacto no tráfego da área central e nos estacionamentos nos anos posteriores.

A metodologia empregada no plano diretor utilizava uma visão global das necessidades na escala "macro" do diagnóstico, voltando-se para a escala "micro", estudando os diferentes setores do sistema por meio de pesquisas e observações complementares no campo, até o detalhamento desejado. Naquela época, o sistema viário urbano, suburbano e rural de São Luís era considerado desenvolvido, devido ao programa de construção rodoviária do DER-MA. Entretanto, seria necessária a complementação da rede existente, aumentando sua capacidade, para dar maior fluidez ao tráfego e melhorar 0 acesso das novas áreas de uso residencial e industrial. Do ponto de vista de transportes, essa complementação consistiu em novas ligações rodoviárias, melhoramentos da rede e redimensionamento dos cruzamentos principais (ibid.).

Diante dessa nova conjuntura, o transporte torna-se um elemento estruturador na dinâmica da cidade e estabelece novos paradigmas nos comportamentos sociais. 0 processo de mobilidade não é apenas algo relacionado com os movimentos de pessoas, ideias e coisas no espaço, mas deve ser compreendido como um elemento transformador nos estudos das ciências sociais. Sendo assim, apresenta-se uma alternativa teórica e metodológica, possibilitando uma visão de mundo social teorizado de acordo com as práticas políticas e econômicas, contemplando novas ideologias envolvidas nos vários tipos de deslocamentos. Nesse contexto, Urry (2007) analisa: 
[...] como as novas tecnologias dos transportes e das comunicações caracterizam sociedades modernas, considerando uma série de novas comunicações, admitindo que o movimento físico pode ser cada vez menos necessário. Fica evidente que o movimento está mais relacionado com um tipo de direito em tais sociedades, como exposto na Declaração das Nações Unidas dos Direitos Universais ou na Constituição da União Europeia. (p. 17; tradução nossa)

Urry (ibid.) apontaria, na maioria das vezes, as ciências sociais enfatizando apenas os padrões gerais individuais de interação entre si e acabava ignorando as infraestruturas físicas e materiais que determinam padrões econômicos, políticos e sociais. Quase todos os pressupostos da mobilidade de infraestrutura imóvel de larga escala possibilitam as sociabilidades na vida diária da população. Em relação a essa infraestrutura imóvel, podemos incluir: as estradas, as vias públicas, as linhas férreas, os encanamentos de abastecimento de água e coleta de esgotos, o cabeamento de comunicações, entre outros.

As diversas formas de relação que envolvem os indivíduos, compreendidas como interações, podem relacionar-se com o conceito de sociabilidade. No entanto, é preciso esclarecer que o simples fato de estar com o outro, para o outro ou contra o outro, por si só, não consiste nessa sociabilidade. Dessa forma, Simmel (2006) esclarece que os homens realizam ações, à medida que os impulsos da vida têm no seu conteúdo a produção da forma de um comportamento desejável aos padrões sociais.

Desde a segunda metade do século $X X$, o sistema de transporte de massa de São Luís passaria a ser estruturado nos ônibus, deixando de se utilizar o bonde elétrico. Nesse sentido, o plano diretor já apresentava a possibilidade de se criarem terminais de transportes coletivos conjugados com estacionamentos, na periferia da cidade, distribuindo os passageiros de ônibus e de carros particulares por meio de micro-ônibus ou bondes modernos (Maranhão, 1977). 0 plano discutia sobre a proximidade do limite de capacidade do sistema de transportes coletivos por ônibus, e a cidade necessitaria de uma nova rede, que poderia ser atendida por outras formas de conduções.

Embora o fato fuja ao escopo do presente trabalho e à realidade atual da cidade, a provável alta densidade da população ao longo do eixo Centro-Anil-Tirirical sugere uma linha simples de monotrilho, com ônibus alimentadores. 0 uso do micro-ônibus poderia ter um papel importante dentro da zona comercial, ligando os dois terminais da avenida Gomes de Castro e do Mercado Público com o precinto de pedestres. (Ibid., p. 52)

As normas propostas por meio do Código de Zoneamento de 1975 baseavam-se em dois tipos de problemas: o controle de usos dentro das diferentes zonas e a sua intensidade. No mecanismo de mercado, esses diferentes usos se localizavam onde ocorreria um equilíbrio entre o preço da terra, o lucro ou o espaço residencial desejado. A interferência do zoneamento, de caráter predominantemente restritivo, afetava esse equilíbrio, resultando nos usos banidos e nos custos de localização mais altos (ibid.).

Burnett (2008) relata que, nos anos de 1980, o Maranhão se viu incluído nos grandes projetos econômicos nacionais, nos novos empreendimentos industriais e de mineração, que 
colocariam a cidade de São Luís novamente em evidência. Essas transformações políticas e econômicas seriam responsáveis pela estruturação dos bairros do Renascença e do Calhau, dando continuidade àquelas mudanças de padrões sociais que ocorreram com maior ênfase na década anterior.

Kesselring (2008, p. 77; tradução nossa) nos diz que a vida moderna reconfigura e reestrutura permanentemente os elementos materiais, sociais e espaciais no ambiente das pessoas, e a modernidade "é criada como um processo não intencional de individualização e desencaixe, e da extensão contínua de redes sociais". As poderosas infraestruturas globais são, portanto, moldadas nos contextos sociais e culturais das sociedades modernas, levando a mobilidade a representar o princípio geral dessa modernidade, equiparando-se com fatores relacionados com a individualidade, racionalidade, igualdade e globalidade.

Esses traços da sociedade moderna surgiram na cidade de São Luís sobre a construção de novas vias, que possibilitariam a ocupação de novos territórios, oferecendo uma visão do futuro e reforçando um modelo de desenvolvimento, que teriam, como eixos norteadores da nova expansão urbana, as pontes sobre 0 rio Anil e a barragem do Rio Bacanga, sendo interligadas com o anel viário, construído em volta do Centro Histórico. Por fim, essas intervenções rodoviárias, propostas pelo poder público para a cidade, seriam estruturas marcantes que definiriam as diretrizes de políticas urbanas de uma nova São Luís que estaria por vir no século XXI.

\section{Considerações finais}

0 transporte urbano é um instrumento de ordenação do conjunto de deslocamentos, que envolvem diferentes ritmos e velocidades, e influenciou de forma significativa na remodelação do espaço geográfico e na sociabilidade (Simme, 2006) dos indivíduos na cidade de São Luís, a partir da segunda metade do século XX. A sociologia apresenta um novo paradigma para a mobilidade urbana, quando trata dos deslocamentos dos indivíduos, que ocorrem nos âmbitos espaciais e sociais. Assim, o estudo da mobilidade não é apenas um aspecto técnico, deve ser considerado num campo científico mais amplo, envolvendo conceitos teóricos das ciências exatas e sociais, tendo em vista a sua análise de forma simultânea.

Compreender a organização das cidades como locais onde são realizados múltiplos deslocamentos traz ao citadino uma perspectiva de futuro que precisa ser observada com maior profundidade, pois o desenvolvimento tecnológico acelera as relações econômicas impostas pelo sistema capitalista, ultrapassando rapidamente as barreiras físicas e geográficas, resultando num novo processo social de interação entre os indivíduos. Essas novas características econômicas se tornam cada vez mais recorrentes, devido ao grande movimento de pessoas, coisas e ideias, em grandes distâncias, num curto espaço de tempo.

A sociedade moderna é mais do que uma sociedade em movimento, observam-se construções sociais relacionadas com um mundo de 
fluxos, concretizadas na concepção e execução de planos e projetos urbanos. A relevância dessas redes nas transformações das estruturas sociais está relacionada com a interação dos indivíduos de diferentes territórios em tempo real. As ideias estão em movimentos contínuos e são elas que criam novas visões de mundo, o que se reflete, a todo instante, em grandes mudanças do comportamento da sociedade em relação ao território ocupado.

Nas últimas décadas, São Luís passou por transformações urbanas e sociais que foram consolidadas na sua paisagem construída. A infraestrutura viária planejada e executada a partir da segunda metade do século XX proporcionou o surgimento de um novo paradigma em relação à ocupação do território, resultando na expansão urbana para a zona norte da Ilha, direcionando a classe de alto poder econômico para localidades próximas à orla marítima. Enquanto isso, outro eixo viário determinava um fluxo oposto para a população de baixa renda, concentrando-a na parte oeste-sul da cidade.

A política de mobilidade desenvolvida pelo poder público, incluindo os transportes e a sua infraestrutura, contribuiu para determinar a urbanização de novos territórios e influenciar nos fluxos da população urbana de São Luís. A "conquista" de novos territórios, também, colaborou para o esvaziamento do Centro Histórico, já que a opção de morar em edifícios antigos coloniais já não mais representava um hábito modernista, resultando na conservação do grande acervo arquitetônico colonial português.

A análise realizada nesta pesquisa, por meio da categoria motility, demonstrou que a infraestrutura provida pelo Estado permitiu 0 acesso de parte dos indivíduos aos meios de mobilidade, pois nem todos tiveram a mesma competência para tirar proveitos do acesso existente. Por fim, tem-se uma última proposição, que está relacionada com a apropriação, ou seja, de que forma as diferentes classes sociais de São Luís se utilizaram do acesso e da competência, para estabelecer uma nova forma de morar e de ocupar o território.

Assim, conclui-se que, quando os indivíduos, nas suas interações, se utilizam de meios tecnológicos e econômicos que não são igualitários na sociedade capitalista, eles contribuem para a criação diferenciada de padrões de sociabilidade. No decorrer da história, novas necessidades surgirão e farão com que as pessoas criem novas ações, tendo em vista garantir o seu acesso, por meio de suas competências, apropriando-se dessas novas formas de vivenciar a cidade, o que resulta na construção de um novo comportamento social.

\section{Marcio Rodrigo da Silva Pereira}

Unidade de Ensino Superior Dom Bosco, Arquitetura e Urbanismo. São Luís, MA/Brasil. marcio.pereira@undb.edu.br.

\section{José 0 . Alcântara Jr.}

Universidade Federal do Maranhão, Programa de Pós-Graduação em Ciências Sociais. São Luís, MA/Brasil.

josealcantarajr@uol.com.br 


\section{Notas}

(1) “(...) políticas urbanas correspondem ao conjunto das políticas públicas e das ações do poder público sobre processos urbanos. Implicam, portanto, um conjunto de metas, objetivos, diretrizes e procedimentos que orientam a ação do poder público em relação a um conjunto de relações, necessidades ou demandas sociais, expressos ou latentes nos aglomerados urbanos" (Alvim, Castro e Zioni, 2010, p. 13).

(2) Robert Moses foi um homem público norte-americano, coordenador do Departamento de Obras, presidente da Comissão de Remoção de Cortiços e do Conselho de Parques de Nova York. Ele dominou o cenário político de Nova York de 1924 a 1968, sendo responsável pela reestruturação de sua região metropolitana, através de um extenso programa de construção de vias expressas, parques e equipamentos públicos (670 quilômetros de vias expressas e 13 pontes, segundo Goldberger, 1981) (Nobre, 2010, p. 4).

(3) Organização das Nações Unidas para Educação, Ciência e Cultura.

(4) Superintendência de Urbanização da Capital.

(5) Também conhecida como a avenida Ana Jansen, que liga o bairro do São Francisco ao da Ponta d'Areia.

\section{Referências}

ALVIM, A.; CASTRO, L.; e ZIONI, S. (2010). "Avaliação de políticas urbanas". In: BENATTI, A. e CASTRO, G (orgs.). Avaliação de políticas urbanas: contexto e perspectivas. São Paulo, Universidade Presbiteriana Mackenzie, Mackpesquisa e Romano Guerra Editora.

ANELLI, R. L. S. (2007). Redes de Mobilidade e Urbanismo em São Paulo: das radiais/perimetrais do Plano de Avenidas à malha direcional PUB. Arquitextos. São Paulo, ano 7, n. 082.00, pp. 01-12.

BRASIL (1974). Lei no. 6.151, de 4 de dezembro de 1974. Dispõe sobre o segundo Plano Nacional de Desenvolvimento (PND) para o período de 1975 a 1979. Disponível em: http://bibspi. planejamento.gov.br/handle/iditem/492. Acesso em: 4 abr 2016.

(2012). Lei no. 12.587, de 3 de janeiro de 2012. Institui as diretrizes da Política Nacional de Mobilidade Urbana e dá outras providências. Disponível em: http://www.planalto.gov.br/ ccivil_03/_ato2011-2014/2012/lei//12587.htm. Acesso em: 6 jan 2017.

BURNETT, C. (2008). Urbanização e desenvolvimento sustentável. A sustentabilidade dos tipos de urbanização em São Luís do Maranhão. São Luís, Editora UEMA.

CAFETEIRA, E. (1994). Reviver. Brasília, Senado Federal, Centro Gráfico.

FERREIRA, A. (2014). A produção do espaço urbano em São Luís do Maranhão: passado e presente; há futuro? São Luís, EDUFMA. 
IBGE (2016). Cidades. Disponível em: http://cidades.ibge.gov.br/xtras/perfil.php?codmun=211130. Acesso em: 4 maio 2016.

KESSELRING, S. (2008). "The Mobile Risk Society". In: WEERT, C.; KAUFMANN, V.; e KESSELRING, S. Tracing mobilities: towards a cosmopolitan perspective. UK, Ashgate.

LOPES, J. (org.) (2008). São Luís Ilha do Maranhão e Alcântara: guia de arquitetura e paisagem. Sevilla, Consejería de Obras Públicas y Transportes, Dirección General de Arquitectura y Vivienda.

MARANHÃO (1977). Plano Diretor de São Luís. São Luís, Secretaria de Planejamento, Sioge.

MESQUITA, R. (1958). Plano de Expansão da Cidade de São Luís. São Luís, DER-MA.

MIRALLES-GUASCH, C. (2002). Ciudad y transporte. El binômio imperfecto. Barcelona, Ariel.

NOBRE. E. A. C. (2010). A atuação do poder público na construção da cidade de São Paulo: a Influência do rodoviarismo no urbanismo paulistano. Disponível em: http://www.fau.usp.br/pesquisa/ napplac/trabalhos/enobre/enobre_art1.pdf. Acesso em 5 jan 2017.

ROLNIK, R. (1997). A cidade e a lei: legislação, política urbana e territórios na cidade de São Paulo. São Paulo, Studio Nobel, Fapesp.

ROLNIK, R. e KLINTOWITZ, D. (2011). (I) Mobilidade na cidade de São Paulo. Estudos avançados. São Paulo, v. 25, n. 71, pp. 89-108.

SANTOS, M. (2013). A urbanização brasileira. São Paulo, Editora da Universidade de São Paulo.

SIMMEL, G. (2006). Questões fundamentais da sociologia: indivíduo e sociedade. Rio de Janeiro, Jorge Zahar.

SOUZA, M. A. A. de (2010). "O II PND e a política urbana brasileira: uma contradição evidente". In: DEÁK, C. e SCHIFFER, S. O processo de urbanização no Brasil. São Paulo, Editora da Universidade de São Paulo.

URRY, J. (2007). Mobilities. Cambridge/Inglaterra, Polity Press.

(2008). "Moving on the mobility turn". In: WEERT, C.; KAUFMANN, V. e KESSELRING, S. Tracing mobilities: towards a cosmopolitan perspective. UK, Ashgate.

VILLAÇA, F. (2001). O espaço intra-urbano no Brasil. São Paulo, Fapesp.

WEERT, C.; KAUFMANN, V. e KESSELRING, S. (2008). Tracing mobilities: towards a cosmopolitan perspective. UK, Ashgate.

Texto recebido em 28/ago/2016

Texto aprovado em 25/out/2016 